\title{
Dinâmica de produção de forragem de gramíneas anuais de inverno em diferentes épocas de semeadura
}

\author{
Forage production dynamics of cool-season annual grasses sowed at different times
}

\author{
Jussara Maria Ferrazza ${ }^{\mathrm{I}}$ André Brugnara Soares ${ }^{\mathrm{I}}$ Thomas Newton Martin ${ }^{\mathrm{II}}$ \\ Alceu Luiz Assmannn ${ }^{\text {III }}$ Francisco Migliorini ${ }^{\mathrm{I}}$ Vinicius Nicola ${ }^{\mathrm{I}}$
}

RESUMO

A determinação da produção de cada planta forrageira, em cada período, ao longo de sua estação de crescimento, é importante para que se possa orientar o planejamento forrageiro. Objetivou-se com este trabalho avaliar a taxa de acúmulo de matéria seca em diferentes forragens de estação fria em épocas de semeadura distintas. O trabalho foi realizado no período de março a novembro de 2009 para avaliar a taxa de acúmulo diária de forragem em forrageiras anuais de inverno (diferentes cultivares (cvs) de aveia, azevém, centeio, trigo e triticale) em quatro épocas de semeadura (11/3, 8/4, 6/5 e 3/6). As produções de forragem foram convertidas em taxas diárias de acúmulo. Verificou-se interação entre as taxas de acúmulo de forrageiras e épocas de semeadura para todos os caracteres avaliados, indicando flexibilidade no planejamento de implantação das forrageiras. As culturas que tiveram destaque foram as aveias brancas, cvs 'UTF Iguaçú' e 'IPR 126', a aveia preta, cv 'IAPAR 61', as cultivares de azevém e centeio, que apresentaram, em média, produção diária de forragem de $51,4 \mathrm{~kg} \mathrm{ha}^{-1}$ após a primeira utilização, demonstrando possuírem elevada capacidade de produção e manutenção da produção, especialmente se semeadas até início de maio.

Palavras-chave: Avena sativa, Avena strigosa, Lolium multiflorum, planejamento forrageiro, Secale cereale, Triticosecale Wittmack, Triticum aestivum.

\section{ABSTRACT}

Forage production evaluation according to forage species and period within growing season is important to adjust forage budget. The aim of this trail was to evaluate forage accumulation rate of cool-season annual grasses on four sowing dates. This study was carried out from March 2009 to November 2009 to evaluate forage accumulation rate on cool-season forage grasses (Black oat, rye, ryegrass, wheat, and triticale) on four sowing dates: March $11^{\text {th }}$, April $8^{\text {th }}$, May $6^{\text {th }}$, and June $3^{\text {rd }}$. Forage production was converted into daily accumulation rate. Significant forage species vs sowing date interaction was verified for all variables analyzed, indicating several possible combinations between forage species and sowing date. Highest production were observed for white oats 'UTF Iguaçú' and 'IPR 126', black oat 'IAPAR 61', annual ryegrass cultivars and rye, which presented average of $51.4 \mathrm{~kg} D M /$ ha after first cut, showing a great performance in terms of forage production and maintenance of their forage production, especially when sowed before early May.

Key words: Avena sativa, Avena strigosa, forage budget, Lolium multiflorum, Secale cereale, Triticosecale Wittmack, Triticum aestivum.

\section{INTRODUÇÃO}

A utilização de forrageiras anuais de inverno constitui uma alternativa de produção de forragem em sistemas de integração lavourapecuária, visando a suprir o déficit forrageiro que ocorre no outono e inverno na Região Sul do Brasil (BALBINOT JUNIOR et al., 2009). Esses períodos, em que as forrageiras de uma estação estão em final de ciclo e as próximas ainda não se encontram aptas para o pastejo, consistem em períodos críticos para a alimentação animal. Na Região Sul do Brasil, as espécies mais utilizadas como forrageiras de inverno em sistemas de produção animal são a aveia preta e o azevém anual (BALBINOT JUNIOR et al.,

IPrograma de Pós-graduação em Agronomia, Universidade Tecnológica Federal do Paraná (UTFPR), Via do Conhecimento, Pato Branco, PR, Brasil.

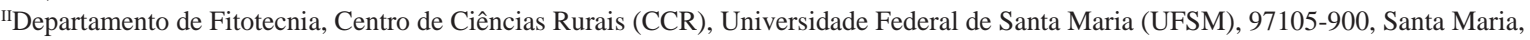
RS, Brasil. E-mail: martin.ufsm@gmail.com. Autor para correspondência.

IIIInstituto Agronômico do Paraná, Pato Branco, PR, Brasil. 
2009), contudo, outras espécies como aveia branca, centeio, triticale e trigo duplo-propósito apresentam resultados interessantes para a produção de forragem (BORTOLINI et al., 2004).

A distribuição da produção de forragem no tempo, entendida como dinâmica de produção, é a que define a magnitude dos vazios forrageiros, os custos da produção e auxilia na tomada de decisão acerca do planejamento forrageiro. Os resultados de produção total não demonstram o comportamento da produção de forragem ao longo da estação fria e, isoladamente, não fornecem as informações necessárias para os técnicos e produtores rurais tomarem as decisões. Desse modo, a avaliação da dinâmica de produção por meio da determinação da taxa de acúmulo diária e mensal da forragem é uma alternativa para a realização de um correto planejamento forrageiro.

Historicamente, na avaliação de forrageiras em parcelas, sob cortes ou sob pastejo, a data de utilização era comum para todas as parcelas, mesmo que tivessem taxas de acúmulo e renovação de tecidos completamente distintas (PRIMAVESI et al., 2002). Atualmente, há um consenso para que as plantas sejam cortadas em função de suas características morfofisiológicas, ou utilizando variáveis relacionadas a essas, como interceptação de radiação, massa de lâminas foliares, senescência de folhas e altura (DA SILVA\& NASCIMENTO JÚNIOR, 2007). No entanto, essa nova metodologia, respeitando a ecofisiologia das plantas, dificulta a comparação das espécies ou dos tratamentos numa mesma base de tempo, pois o corte/pastejo de um tratamento pode acontecer muito antes ou depois de outro tratamento. Provavelmente, devido a isso, os pesquisadores tenham preferido reportar e discutir dados apenas sobre a produção total de forragem (KIRCHNER et al., 2010; PIN et al., 2011). Baseado nesse contexto, objetivou-se com este trabalho, avaliar a dinâmica de produção de forrageiras anuais de inverno em quatro épocas de semeadura, por meio da avaliação da taxa de acúmulo diária de matéria seca, como indicador da dinâmica de produção de forragem.

\section{MATERIAL E MÉTODOS}

O experimento foi conduzido no período de 11 de março a 30 de outubro de 2009, na área experimental do Instituto Agronômico do Paraná (IAPAR), Pato Branco, situado na região fisiográfica denominada Terceiro Planalto Paranaense, com coordenadas $26^{\circ} 07^{\prime} \mathrm{S}$ e $52^{\circ} 41^{\prime} \mathrm{W}$, altitude de $700 \mathrm{~m}$. O clima da região é o subtropical úmido do tipo (Cfa), conforme classificação de Köppen (MAACK,
1968). A caracterização meteorológica do período de estudo em relação à média histórica está apresentada na figura 1. O solo predominante na área pertence à unidade de mapeamento LATOSSOLO VERMELHO Distroférrico úmbrico, textura argilosa, álico, fase floresta subtropical perenifólia, relevo ondulado (BHERING et al., 2008). A análise química revelou os seguintes valores: $\mathrm{pH}$ em $\mathrm{CaCl}=5,1$; M.O.=40,21 $\mathrm{g} \mathrm{dm}^{-3} ; \mathrm{P}=13,44 \mathrm{mg} \mathrm{dm}^{-3} ; \mathrm{K}=0,50 \mathrm{cmol}$ $\mathrm{dm}^{-3} ; \quad \mathrm{Cu}=3,23 \mathrm{mg} \quad \mathrm{dm}^{-3} ; \quad \mathrm{Fe}=26,03 \mathrm{mg} \quad \mathrm{dm}^{-3}$; $\mathrm{Zn}=1,64 \mathrm{mg} \mathrm{dm}^{-3} ; \mathrm{MN}=0,00 \mathrm{mg} \mathrm{dm}^{-3} ; \mathrm{Al}^{+3}=0,00 \mathrm{cmol}$ $\mathrm{dm}^{-3} ; \mathrm{H}+\mathrm{Al}=4,28 \mathrm{cmol}_{\mathrm{dm}}^{-3} ; \quad \mathrm{Ca}=7,1 \mathrm{cmol} \mathrm{dm}^{-3}$; $\mathrm{Mg}=3,1 \mathrm{cmol} \mathrm{dm}^{-3} ; \mathrm{SB}=10,75 \mathrm{cmol} \mathrm{dm}^{-3} ; \mathrm{V}=71,52 \%$.

A área experimental era manejada em sistema plantio direto: com rotação de soja e milho no verão e cultivo no inverno de aveia como cobertura ou trigo para produção agrícola. Após a colheita da soja, realizou-se a adubação, de acordo com as recomendações técnicas da COMISSÃO DE QUÍMICA E FERTILIDADE DO SOLO (2004). A adubação foi realizada concomitante à abertura dos sulcos, por meio de uma semeadora com espaçamento entre fileiras de $17 \mathrm{~cm}$, consistindo a adubação de base de $45 \mathrm{~kg} \mathrm{ha}^{-1}$ de $\mathrm{P}_{2} \mathrm{O}_{5}$. As sementes foram distribuídas manualmente e uniformemente em sulcos e incorporadas ao solo a $2 \mathrm{~cm}$ de profundidade. Aplicou-se $100 \mathrm{~kg}_{\text {de }} \mathrm{N}_{\text {ha }}{ }^{-1}$ em cobertura na forma de ureia, parcelada em duas vezes, distribuídas aos 30 e 60 dias após a semeadura.

O delineamento experimental utilizado foi o de blocos ao acaso com três repetições em parcelas subdivididas, sendo os tratamentos distribuídos em um fatorial $(4 \times 16)$, utilizando-se épocas de semeadura (parcelas) e forrageiras (subparcelas). As semeaduras foram realizadas com intervalo de vinte e oito dias, correspondendo às seguintes datas: 11/03, 08/04, 06/05 e 03/06 de 2009. As subparcelas foram compostas por 11 fileiras com três metros de comprimento, com área útil de seis metros quadrados, totalizando $1600 \mathrm{~m}^{2}$.

As forrageiras e as quantidades de sementes utilizadas foram as seguintes, respectivamente: aveia branca (Avena sativa L.) cultivares(cvs) 'FAPA 2' (350 sementes $\mathrm{m}^{-2}$ ), 'FUNDACEP FAPA 43' (350 sementes $\mathrm{m}^{-2}$ ), 'IPR 126' (250 sementes $\mathrm{m}^{-2}$ ) e 'UTF Iguaçú' (350 sementes $\mathrm{m}^{-2}$ ); aveia preta (Avena strigosa Schreb) cvs 'Aveia Preta Comum' (350 sementes $\mathrm{m}^{-2}$ ), 'UPF 21-Moreninha' (400 sementes $\mathrm{m}^{-2}$ ), 'Agro Planalto' (300 sementes $\mathrm{m}^{-2}$ ), 'Agro Coxilha' (300 sementes $\mathrm{m}^{-2}$ ), 'Agro Zebu' (300 sementes $\mathrm{m}^{-2}$ ) e 'IAPAR 61' (300 sementes $\mathrm{m}^{-2}$ ); azevém (Lolium multiflorum Lam.) cvs 'Comum' (350 sementes $\mathrm{m}^{-2}$ ) e 'São Gabriel' (350 sementes 


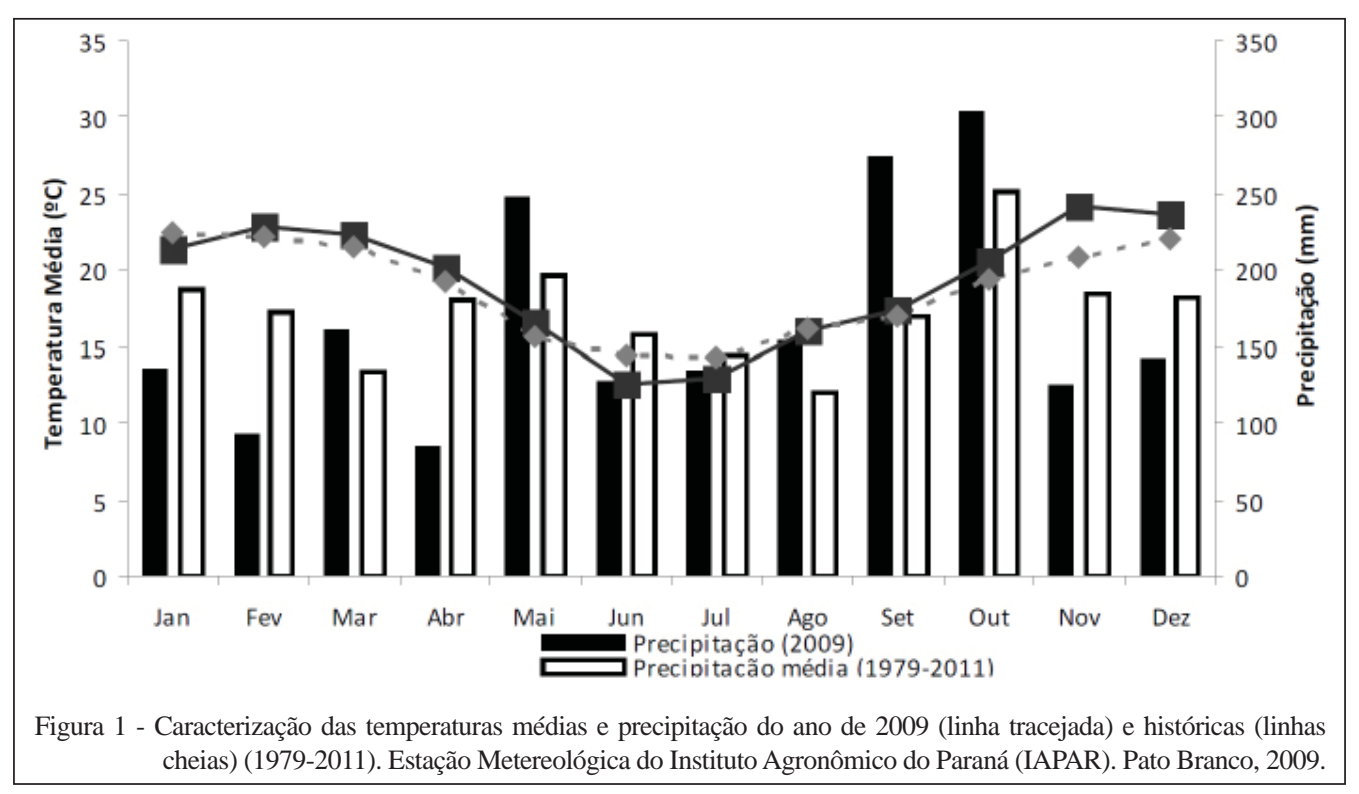

$\mathrm{m}^{-2}$ ); centeio (Secale cereale L.) cV 'Serrano' (350 sementes $\mathrm{m}^{-2}$ ); triticale ( $\boldsymbol{X}$ Triticosecale Wittmack) cvs 'TCL 399' (450 sementes $\mathrm{m}^{-2}$ ), 'POLO 981' (450 sementes $\mathrm{m}^{-2}$ ) e trigo duplo-propósito (Triticum aestivum L.) cv. 'BRS tarumã' (350 sementes $\mathrm{m}^{-2}$ ).

Os cortes foram realizados quando a média de altura das plantas atingiam as estaturas pré definidas, sendo, para cultivares de azevém, trigo e centeio, de $25 \mathrm{~cm}$; as espécies e/ou cultivares de aveia e cultivares de triticale de $30 \mathrm{~cm}$, todas as plantas cortadas a sete centímetros do nível do solo. Todas as forrageiras foram cortadas à altura correspondente a 95\% de interceptação luminosa para essas espécies (DA SILVA \& NASCIMENTO JÚNIOR, 2007).

Com o auxílio de um quadro de $0,4 \mathrm{~m}^{2}$ e de uma tesoura de esquila, as amostras foram coletadas, identificadas, pesadas e colocadas em sacos de papel, secas em estufa de ventilação forçada a $60^{\circ} \mathrm{C}$ até massa constante. Posteriormente, foram pesadas para a obtenção do percentual de matéria seca (MS). Subsequente aos cortes das amostras, as parcelas foram uniformizadas para a altura residual padronizada, por meio de uma roçadeira costal.

As variáveis avaliadas foram: produção de forragem por corte e taxa de acúmulo diária (TA) de forragem entre os cortes, estimando-se, assim: taxa de acúmulo diária de forragem nos meses de março (TAmar, kg ha-1 dia $^{-1}$ de MS), abril (TAabr, kg ha-1 $\mathrm{dia}^{-1}$ de MS), maio (TAmai, kg ha ${ }^{-1} \operatorname{dia}^{-1} \mathrm{de}$ MS) e junho (TAjun, kg ha-1 dia $^{-1}$ de MS), julho (TAjul, $\mathrm{kg} \mathrm{ha}^{-1} \mathrm{dia}^{-1}$ de MS), agosto (TAago, $\mathrm{kg} \mathrm{ha}^{-1} \mathrm{dia}^{-1} \mathrm{de}$ MS), setembro (TAset, $\mathrm{kg} \mathrm{ha}^{-1} \mathrm{dia}^{-1}$ de MS) e outubro (TAout, kg ha-1 dia $^{-1}$ de MS). A taxa de acúmulo antes do primeiro corte foi calculada dividindo-se a produção do primeiro corte pelo número de dias entre a semeadura e o primeiro corte. Posteriormente, as TA foram calculadas entre os cortes e, após, fez-se a ponderação das TA referentes a cada mês, utilizando a seguinte equação:

$\mathrm{TA}_{\mathrm{mi}}=$
$\left.\left.\mathrm{NDM}_{\mathrm{x}, \mathrm{x}+1}\right)\right] / \mathrm{ND}_{\mathrm{mi}}$,

em que: $\mathrm{TA}_{\mathrm{mi}}$ refere-se a taxa de acúmulo de determinado mês $i$; $\mathrm{TA}_{\mathrm{x}, \mathrm{x}-1}$ : taxa de acúmulo entre o corte atual (x) e o corte anterior (x-1); $\operatorname{NDM}_{\mathrm{x}, \mathrm{x}-1}$ : número de dias do mês $i$ entre os cortes $\mathrm{x}$ e $\mathrm{x}-1$; $\mathrm{TA}_{\mathrm{x}, \mathrm{x}+1}$ : taxa de acúmulo entre o corte atual $(\mathrm{x})$ e o próximo corte $(\mathrm{x}+1) ; \mathrm{NDM}_{\mathrm{x}, \mathrm{x}+1}$ : número de dias do mês $i$ entre os cortes $\mathrm{x}$ e $\mathrm{x}+1$ e $\mathrm{ND}_{\mathrm{mi}}$ : número de dias do mês $i$.

Os resultados obtidos foram submetidos à análise de variância e as análises complementares foram realizadas por meio do teste de Scott-Knott, ambos a 5\% de probabilidade de erro, utilizando-se o software Genes (CRUZ, 2001).

\section{RESULTADOS E DISCUSSÃO}

A partir dos resultados obtidos, verificouse que houve interação $(\mathrm{P}<0,05)$ entre as épocas e as forrageiras para todas as variáveis avaliadas. Para taxa de acúmulo diária de forragem no mês março (Tabela 1 ), obtiveram-se rendimentos de forragem somente para a primeira época de semeadura, pois somente havia sido realizada a primeira semeadura até o mês de março. Com relação às forrageiras, observou-se que a maior TA foi obtida pelo triticale POLO 981, 
Tabela 1 - Taxa de acúmulo diária de forragem (kg ha ${ }^{-1}$ dia $^{-1}$ de MS) nos meses de março (TAmar), abril (TAabr), maio (TAmai) e junho (TAjun). Pato Branco, 2010.

\begin{tabular}{|c|c|c|c|c|c|c|c|c|}
\hline \multirow[t]{2}{*}{ For* } & \multicolumn{8}{|c|}{--Datas de semeadura--------- } \\
\hline & $11 / 03$ & $08 / 04$ & 06/05 & 03/06 & $11 / 03$ & $08 / 04$ & 06/05 & 03/06 \\
\hline AzCo & $6,05 c^{* *}$ & - & - & - & $6,05 \mathrm{cB}$ & $17,54 \mathrm{bA}$ & - & - \\
\hline AzSG & $11,19 \mathrm{c}$ & - & - & - & $11,19 \mathrm{cA}$ & $14,59 \mathrm{bA}$ & - & - \\
\hline AB2 & $15,03 b$ & - & - & - & $15,03 \mathrm{bB}$ & $23,32 \mathrm{aA}$ & - & - \\
\hline AB43 & $20,34 a$ & - & - & - & $20,34 \mathrm{aA}$ & $21,89 \mathrm{aA}$ & - & - \\
\hline AB126 & $19,48 a$ & - & - & - & $19,48 \mathrm{aA}$ & 20,32bA & - & - \\
\hline ABIg. & $17,78 \mathrm{a}$ & - & - & - & $17,78 \mathrm{aB}$ & $25,44 \mathrm{aA}$ & - & - \\
\hline APCo. & $16,00 \mathrm{~b}$ & - & - & - & $16,00 \mathrm{bB}$ & $24,10 \mathrm{aA}$ & - & - \\
\hline APMo. & $16,28 b$ & - & - & - & $16,28 \mathrm{bA}$ & $20,44 \mathrm{bA}$ & - & - \\
\hline APPla. & $14,18 b$ & - & - & - & $14,18 \mathrm{bB}$ & $22,25 \mathrm{aA}$ & - & - \\
\hline APCox. & $15,30 \mathrm{~b}$ & - & - & - & $15,30 \mathrm{bA}$ & $17,62 \mathrm{bA}$ & - & - \\
\hline APZ & 18,99a & - & - & - & $18,99 \mathrm{aA}$ & $19,60 \mathrm{bA}$ & - & - \\
\hline AP61 & $14,39 b$ & - & - & - & $14,39 \mathrm{bB}$ & $22,85 \mathrm{aA}$ & - & - \\
\hline Cent.Ser. & $20,52 a$ & - & - & - & $20,52 \mathrm{aA}$ & $19,96 \mathrm{bA}$ & - & - \\
\hline T.Tarumã & 19,73a & - & - & - & $19,73 a A$ & $24,05 \mathrm{bA}$ & - & - \\
\hline Trit.399 & $15,93 b$ & - & - & - & 15,93bB & $22,53 \mathrm{aA}$ & - & - \\
\hline Trit.981 & $23,31 a$ & - & - & - & $23,31 \mathrm{aA}$ & $25,59 \mathrm{aA}$ & - & - \\
\hline Média & 4,13 & CV(\%) & 38,86 & & Média & 9,47 & CV(\%) & 28,69 \\
\hline AzCo & $6,05 \mathrm{eB}$ & $17,54 \mathrm{aA}$ & $17,88 \mathrm{bA}$ & - & 19,78eB & $31,37 \mathrm{dA}$ & 17,88bB & $27,35 \mathrm{aA}$ \\
\hline AzSG & $11,19 \mathrm{eA}$ & $14,59 \mathrm{aA}$ & 19,95bA & - & $24,42 \mathrm{eA}$ & $27,67 \mathrm{dA}$ & $19,95 \mathrm{bA}$ & $17,53 \mathrm{aA}$ \\
\hline AB2 & $48,76 \mathrm{cA}$ & $23,32 \mathrm{aC}$ & $32,30 \mathrm{aB}$ & - & $46,92 \mathrm{dA}$ & $47,64 \mathrm{bA}$ & $32,30 \mathrm{aB}$ & $22,79 \mathrm{aC}$ \\
\hline AB43 & $63,18 \mathrm{bA}$ & $21,89 \mathrm{aB}$ & $27,15 \mathrm{aB}$ & - & $62,45 \mathrm{cA}$ & $51,04 \mathrm{bB}$ & $27,15 \mathrm{aC}$ & $19,65 \mathrm{aC}$ \\
\hline AB126 & $79,55 \mathrm{aA}$ & $20,32 \mathrm{aB}$ & $18,43 \mathrm{bB}$ & - & $88,95 \mathrm{aA}$ & $75,20 \mathrm{aB}$ & $18,43 \mathrm{bC}$ & $19,74 \mathrm{aC}$ \\
\hline ABIg. & $53,38 \mathrm{cA}$ & $25,44 \mathrm{aB}$ & 31,86aB & - & $55,19 \mathrm{cA}$ & $54,18 \mathrm{bA}$ & 31,86aB & $20,18 \mathrm{aC}$ \\
\hline APCo. & 46,37cA & $24,10 \mathrm{aB}$ & $20,52 b B$ & - & $28,42 \mathrm{eB}$ & $41,01 \mathrm{cA}$ & $31,24 \mathrm{aB}$ & $19,33 \mathrm{aC}$ \\
\hline APMo. & $43,19 \mathrm{cA}$ & $20,44 \mathrm{aB}$ & $20,34 \mathrm{bB}$ & - & $28,53 \mathrm{eA}$ & $35,45 \mathrm{cA}$ & $33,86 a A$ & $20,74 \mathrm{aB}$ \\
\hline APPla. & $37,52 \mathrm{dA}$ & $22,25 \mathrm{aB}$ & $21,24 \mathrm{bB}$ & - & $25,47 \mathrm{eB}$ & $48,41 \mathrm{bA}$ & 29,93aB & $21,76 \mathrm{aB}$ \\
\hline APCox. & $44,80 \mathrm{cA}$ & $17,62 \mathrm{aB}$ & 19,96bB & - & $34,59 \mathrm{eB}$ & $48,49 \mathrm{bA}$ & $29,80 \mathrm{aB}$ & $21,88 \mathrm{aC}$ \\
\hline APZ & $48,51 \mathrm{cA}$ & 19,60aB & 17,75bB & - & $30,22 \mathrm{eB}$ & $43,02 \mathrm{cA}$ & 28,01aB & $22,56 \mathrm{aB}$ \\
\hline AP61 & 46,79cA & $22,85 \mathrm{aB}$ & $28,19 \mathrm{aB}$ & - & $44,75 \mathrm{dA}$ & 38,79cA & $28,19 \mathrm{aB}$ & $19,20 \mathrm{aB}$ \\
\hline Cent.Ser. & $32,79 \mathrm{dA}$ & $19,96 \mathrm{aB}$ & $26,43 a A$ & - & $62,23 \mathrm{cA}$ & $52,90 \mathrm{bB}$ & $26,43 \mathrm{aC}$ & $15,47 \mathrm{aD}$ \\
\hline T.Tarumã & $33,05 \mathrm{dA}$ & $24,05 \mathrm{aB}$ & $16,27 \mathrm{bC}$ & - & 57,81cA & $54,56 \mathrm{bA}$ & $16,27 \mathrm{bB}$ & $16,62 \mathrm{aB}$ \\
\hline Trit.399 & $28,27 \mathrm{dA}$ & $22,53 a A$ & $23,38 \mathrm{bA}$ & - & $70,85 \mathrm{bA}$ & $51,78 \mathrm{bB}$ & $23,38 b C$ & $21,25 \mathrm{aC}$ \\
\hline Trit.981 & $37,83 \mathrm{dA}$ & $25,59 \mathrm{aB}$ & $24,89 \mathrm{aB}$ & - & $74,25 \mathrm{bA}$ & $71,61 \mathrm{aA}$ & $24,89 \mathrm{aB}$ & $18,06 \mathrm{aB}$ \\
\hline Média & 21,40 & CV(\%) & 18,70 & & Média & 35,49 & CV(\%) & 15,64 \\
\hline
\end{tabular}

*For.: forrageiras: Az Co: az. Comum; Az SG.: az. São Gabriel; AB 2: av. branca FAPA 2; AB 43: av. branca Fundacep FAPA 43; AB 126: av. branca IPR 126; AB Ig.: av. branca UTF Iguaçu; AP Co.: av. preta Comum; AP Mo.: av. preta UPF 21-Moreninha; AP Pla.: av. preta Planalto; AP Cox.: av. preta Coxilha; AP Z.: av. preta Agro Zebu; AP 61: av. preta IAPAR 61; Cent. Ser.: cent. Serrano; T. Tarumã: trigo BRS Tarumã; Trit. 399: trit. TCL 399 e Trit. 981: trit. Pólo 981. **Médias seguidas por letras distintas maiúsculas na horizontal e letras minúsculas na vertical constituem grupo estatisticamente heterogêneo $(\mathrm{P}<0,05)$.

que não diferiu do Centeio Serrano, das aveias branca FAPA 43, IPR 126 e UTF Iguaçú, do trigo BRS Tarumã, e da aveia preta Agro Zebu, demonstrando uma precocidade de produção dessas forrageiras, podendo ser alternativas para o forrageamento de outono, como indicado por FLORES et al. (2008). As menores TA obtidas pelas cultivares de azevém se deve à espécie necessitar de temperaturas mais baixas para um bom desenvolvimento inicial, fato não observado durante mês de março, o que levou à ocorrência do primeiro corte somente no mês de junho.

Para taxa de acúmulo diária de forragem no mês de abril (Tabela 1), observam-se os mesmos valores da primeira época de semeadura, devido ao 
primeiro corte ter ocorrido somente nos meses de maio e junho. Isso ocorre porque, primeiramente, foi realizado o cálculo de acúmulo de forragem desde o dia da semeadura até o primeiro corte, e não somente após o início da utilização das plantas. Dessa forma, como o primeiro corte ocorreu somente em maio, os valores de TA dos meses de março e abril foram iguais. Ao contrário do mês de março, obtevese acúmulo de forragem para a segunda época de semeadura, a qual foi realizada no dia oito de abril. Observou-se que a segunda época proporcionou maiores TA de forragem para todas as forrageiras, indicando-a como a ideal para atender a demanda de forragem para o mês de abril em regime de cortes. $\mathrm{Na}$ segunda época, a maior TA também foi obtida pelo triticale POLO 981, não diferindo estatisticamente das aveias brancas FAPA 2, FAPA 43 e UTF Iguaçú, das aveias pretas Comum, Agro Planalto e IAPAR 61, e do triticale TCL 399. Semeando aveia+azevém, triticale+azevém e centeio+azevém em abril, ROSO et al. (2000) obtiveram, respectivamente, durante o mês de abril, TA de 26,2, 25,5 e 36,2kg ha-1 $\mathrm{dia}^{-1}$ de MS, valores superiores aos obtidos neste trabalho, o que provavelmente ocorreu devido à densidade de semeadura utilizada pelos autores ter sido muito superior à utilizada neste trabalho, acarretando maiores produções.

Durante o mês de maio, observa-se que a primeira época de semeadura proporcionou maiores TA para todas as forrageiras, ao contrário da segunda e terceira épocas de semeadura, nas quais as plantas estavam no início de desenvolvimento e ainda não havia ocorrido o primeiro corte, como na primeira época de semeadura. Sabe-se que, no mês de maio, ocorre o grande déficit forrageiro no sul do País, pois as forrageiras de verão estão encerrando seu desenvolvimento e as de inverno ainda não estão aptas para pastejo (ROCHA et al., 2007). Os resultados deste trabalho indicam que é possível obter com a aveia branca IPR 126, quando semeada no mês de março, produção de forragem diária de até 79,55kg de MS ha-1 ${ }^{-1}$ podendo suprir, dessa forma, o déficit forrageiro. Observou-se que as cultivares de azevém apresentaram menores TA diárias de forragem no mês de maio quando semeadas em março, do que quando semeados em abril e maio, indicando que semeaduras mais precoces para essa espécie não favorecem seu desenvolvimento. De acordo com NELSON et al. (1995), isso ocorre provavelmente por serem gramíneas que se desenvolvem favoravelmente em clima subtropical temperado.

Observou-se que a primeira e a segunda épocas de semeadura proporcionaram TA diária de forragem, no mês de junho (Tabela 1), superiores em relação a terceira e quarta épocas de semeadura. Desse modo, quando se deseja uma quantidade maior de forragem diária nesse mês, preferencialmente, a semeadura deve ser realizada em março ou abril. Porém, as cultivares de azevém mantiveram suas produções estáveis, independente da época de semeadura. A maior TA foi obtida pela aveia branca IPR 126 com 88,95kg ha-1 $\mathrm{dia}^{-1} \mathrm{de}$ MS na primeira época de semeadura e a menor pelo centeio Serrano com 15,47 $\mathrm{kg} \mathrm{ha}^{-1} \mathrm{dia}^{-1} \mathrm{de}$ MS na quarta época, na qual não houve diferença entre as forrageiras. Observa-se diferença de produtividade $(\mathrm{P}<0,05)$ entre as aveias brancas e pretas. A baixa produtividade observada nas aveias pretas, exceto para a aveia IAPAR 61, é devido ao seu ciclo precoce e pelas características morfológicas, por possuir porte mais ereto e apresentarem um dossel forrageiro menos denso que as aveias brancas. Autores como ROSO et al. (2000) obtiveram TA de 34,7, 40,8 e 28,63kg ha-1 $\mathrm{dia}^{-1}$ de MS, respectivamente, para as misturas triticale+azevém, aveia+azevém e centeio+azevém, quando semeados em abril.

Em relação à taxa de acúmulo diária de forragem no mês de julho (Tabela 2), observou-se que a terceira época foi a que proporcionou maiores produções para todas as forrageiras. Observa-se que, para as cultivares de azevém, trigo, triticale POLO 981 e aveia branca IPR 126 não houve diferença entre as três primeiras épocas de semeadura, indicando que, semeando essas forrageiras em março, abril ou maio, a TA diária de forragem no mês de julho tende a ser a mesma. Mas, se a falta de forragem para determinada situação é nos meses de junho e julho, a recomendação é utilizar as duas primeiras épocas de semeadura, porque, desse modo, o potencial genético dessas forrageiras, em condições climáticas favoráveis, exteriorizam maiores produções (Tabela 1 e Tabela 2). Em trabalho realizado por AGUINAGA et al. (2008) com pastagens de aveia+azevém semeada em maio e manejada em diversas alturas, os autores obtiveram, em média, TA diária de forragem, durante o período de 21 de julho a 22 de agosto, de $89,14 \mathrm{~kg}$, valores bastante superiores ao obtidos neste trabalho, com culturas solteiras sobre regime de corte. Já CARVALHO et al. (2010), em pastagem de aveia+azevém (semeado em maio), manejada em quatro diferentes alturas, obteve, na média, durante o período de três de julho a cinco de agosto, TA de $67,9 \mathrm{~kg} \mathrm{ha}^{-1} \mathrm{dia}^{-1} \mathrm{de} \mathrm{MS}$, corroborando os resultados deste trabalho.

Observou-se que as maiores taxas de acúmulo diário de forragem no mês de agosto 
Tabela 2 - Taxa de acúmulo diária de forragem (kg ha ${ }^{-1}$ dia $^{-1}$ de MS) nos meses de julho (TAjul), agosto (TAago), setembro (TAset) e outubro (TAout). Pato Branco, 2010.

\begin{tabular}{|c|c|c|c|c|c|c|c|c|}
\hline \multirow[t]{2}{*}{ For.* } & \multicolumn{8}{|c|}{-Datas de semeadura---- } \\
\hline & $11 / 03$ & 08/04 & 06/05 & 03/06 & $11 / 03$ & $08 / 04$ & 06/05 & 03/06 \\
\hline $\mathrm{Az}$ Co & $67,02 \mathrm{aA} * *$ & $73,76 \mathrm{aA}$ & $69,79 \mathrm{aA}$ & $27,35 \mathrm{aB}$ & $56,9 \mathrm{aB}$ & 70,0aA & $65,8 \mathrm{aA}$ & $49,8 \mathrm{bB}$ \\
\hline Az SG & $59,47 \mathrm{aA}$ & $67,79 \mathrm{aA}$ & $67,21 \mathrm{aA}$ & $17,53 \mathrm{bB}$ & $65,0 \mathrm{aA}$ & $62,9 \mathrm{aA}$ & $60,2 \mathrm{aA}$ & $59,4 \mathrm{bA}$ \\
\hline AB 2 & 53,59bA & $58,30 \mathrm{bA}$ & $58,30 \mathrm{bA}$ & $22,79 \mathrm{aB}$ & $40,4 \mathrm{bB}$ & $41,2 \mathrm{bB}$ & $50,1 \mathrm{bB}$ & $62,4 \mathrm{bA}$ \\
\hline $\mathrm{AB} 43$ & $56,07 \mathrm{bB}$ & $54,13 \mathrm{bB}$ & 71,90aA & $19,65 \mathrm{bC}$ & $60,9 \mathrm{aB}$ & $58,2 \mathrm{aB}$ & $60,5 \mathrm{aB}$ & $75,0 \mathrm{aA}$ \\
\hline AB 126 & $61,03 \mathrm{aA}$ & $64,68 \mathrm{aA}$ & $61,04 \mathrm{aA}$ & $19,74 \mathrm{bB}$ & $38,2 \mathrm{bA}$ & $45,3 \mathrm{bA}$ & $46,1 \mathrm{bA}$ & $46,6 \mathrm{bA}$ \\
\hline AB Ig. & $52,59 \mathrm{bB}$ & $54,19 \mathrm{bB}$ & $68,38 \mathrm{aA}$ & $20,18 b C$ & $50,6 \mathrm{aB}$ & $53,0 \mathrm{bB}$ & $59,9 \mathrm{aB}$ & $70,8 \mathrm{aA}$ \\
\hline AP Co. & $36,58 \mathrm{~dB}$ & $31,47 c \mathrm{c}$ & $45,79 \mathrm{cA}$ & $25,21 \mathrm{aC}$ & $36,4 \mathrm{bB}$ & $24,3 \mathrm{cB}$ & $32,7 \mathrm{cB}$ & $57,8 \mathrm{bA}$ \\
\hline AP Mo. & $42,04 \mathrm{cB}$ & $32,47 \mathrm{cC}$ & 53,03bA & $25,63 \mathrm{aC}$ & $39,2 \mathrm{bB}$ & $28,0 \mathrm{cB}$ & $37,6 \mathrm{cB}$ & $59,3 \mathrm{bA}$ \\
\hline AP Pla. & $34,17 \mathrm{dA}$ & $25,99 \mathrm{~dB}$ & $42,63 c A$ & $26,69 \mathrm{aB}$ & $35,4 \mathrm{bB}$ & $14,5 \mathrm{cC}$ & $30,4 \mathrm{cB}$ & $59,8 \mathrm{bA}$ \\
\hline AP Cox. & $28,62 \mathrm{~dB}$ & $23,94 \mathrm{~dB}$ & $43,82 \mathrm{cA}$ & $27,62 \mathrm{aB}$ & $26,3 \mathrm{bB}$ & $23,5 \mathrm{cB}$ & $26,9 \mathrm{cB}$ & $56,6 \mathrm{bA}$ \\
\hline AP Z & $34,99 \mathrm{~dB}$ & $24,78 \mathrm{~dB}$ & $50,59 \mathrm{bA}$ & $28,50 \mathrm{aB}$ & $35,6 \mathrm{bB}$ & $19,4 \mathrm{cC}$ & $38,1 \mathrm{cB}$ & $54,9 \mathrm{bA}$ \\
\hline AP 61 & $41,31 \mathrm{cB}$ & $32,86 \mathrm{cC}$ & $56,81 \mathrm{bA}$ & $19,29 b D$ & $34,4 \mathrm{bB}$ & $27,3 \mathrm{cB}$ & $40,4 \mathrm{cB}$ & $54,9 \mathrm{bA}$ \\
\hline Cent.Ser. & $47,95 \mathrm{cB}$ & $44,26 b B$ & $57,61 \mathrm{bA}$ & $15,47 \mathrm{bC}$ & $41,1 \mathrm{bB}$ & $42,0 \mathrm{bB}$ & $48,7 \mathrm{bB}$ & $74,2 \mathrm{aA}$ \\
\hline T Tarumã & 45,10cA & $51,49 \mathrm{bA}$ & $51,40 \mathrm{bA}$ & $16,62 \mathrm{bB}$ & $38,8 \mathrm{bB}$ & $38,8 \mathrm{bB}$ & $47,3 \mathrm{bA}$ & $51,0 \mathrm{bA}$ \\
\hline Trit. 399 & $44,42 \mathrm{cB}$ & $54,28 \mathrm{bA}$ & 56,89bA & $21,25 b C$ & $29,7 \mathrm{bB}$ & $47,4 \mathrm{bA}$ & $56,7 \mathrm{aA}$ & $51,5 \mathrm{bA}$ \\
\hline Trit. 981 & $45,52 \mathrm{cA}$ & $50,55 \mathrm{bA}$ & $53,58 \mathrm{bA}$ & $18,06 \mathrm{bB}$ & $41,6 \mathrm{bA}$ & $45,1 \mathrm{bA}$ & $50,1 \mathrm{bA}$ & $52,3 \mathrm{bA}$ \\
\hline Média & 43,06 & CV(\%) & 12,21 & & Média & 46,91 & CV(\%) & 14,18 \\
\hline Az Co & 43,52bC & $59,84 \mathrm{aB}$ & $60,85 \mathrm{aB}$ & $69,01 \mathrm{bA}$ & $47,88 \mathrm{bC}$ & $64,63 \mathrm{aB}$ & $76,53 \mathrm{aA}$ & $60,72 \mathrm{aB}$ \\
\hline Az SG & 69,19aA & $55,63 \mathrm{aB}$ & $52,55 \mathrm{bB}$ & $50,83 \mathrm{~dB}$ & $66,62 \mathrm{aA}$ & $60,82 \mathrm{aA}$ & $67,94 \mathrm{bA}$ & $66,40 \mathrm{aA}$ \\
\hline AB 2 & 29,94dA & $33,85 \mathrm{cA}$ & 33,89dA & $40,72 \mathrm{eA}$ & $0,00 \mathrm{~dB}$ & $30,94 \mathrm{cA}$ & $0,00 \mathrm{eB}$ & $34,24 \mathrm{cA}$ \\
\hline $\mathrm{AB} 43$ & 48,60bB & $45,46 \mathrm{bB}$ & $40,34 \mathrm{cB}$ & 76,87aA & $0,00 \mathrm{dA}$ & $0,00 \mathrm{dA}$ & $0,00 \mathrm{eA}$ & $0,00 \mathrm{eA}$ \\
\hline AB 126 & $28,33 \mathrm{~dB}$ & $25,88 \mathrm{~dB}$ & $31,96 \mathrm{~dB}$ & $38,83 \mathrm{eA}$ & $29,24 \mathrm{cB}$ & $27,14 \mathrm{cB}$ & $44,43 \mathrm{cA}$ & $25,69 \mathrm{~dB}$ \\
\hline AB Ig. & $36,40 \mathrm{cB}$ & 44,96bA & 44,71bA & $44,70 \mathrm{eA}$ & $33,29 \mathrm{cA}$ & $27,35 \mathrm{cB}$ & $39,52 \mathrm{cA}$ & $34,58 \mathrm{cA}$ \\
\hline AP Co. & $0,00 \mathrm{eB}$ & $0,00 \mathrm{fB}$ & $0,00 \mathrm{fB}$ & $24,04 \mathrm{fA}$ & $0,00 \mathrm{dA}$ & $0,00 \mathrm{dA}$ & $0,00 \mathrm{eA}$ & $0,00 \mathrm{eA}$ \\
\hline AP Mo. & $0,00 \mathrm{eB}$ & $26,40 \mathrm{~dB}$ & 29,79dB & $43,40 \mathrm{eA}$ & $0,00 \mathrm{dC}$ & $0,00 \mathrm{dC}$ & $27,91 \mathrm{~dB}$ & $45,01 \mathrm{bA}$ \\
\hline AP Pla. & $0,00 \mathrm{eB}$ & $0,00 \mathrm{fB}$ & $0,00 \mathrm{fB}$ & $20,87 f A$ & $0,00 \mathrm{dA}$ & $0,00 \mathrm{dA}$ & $0,00 \mathrm{eA}$ & $0,00 \mathrm{eA}$ \\
\hline AP Cox. & $0,00 \mathrm{eB}$ & $29,74 \mathrm{dA}$ & $0,00 \mathrm{fB}$ & $25,12 \mathrm{fA}$ & $0,00 \mathrm{dA}$ & $0,00 \mathrm{dA}$ & $0,00 \mathrm{eA}$ & $0,00 \mathrm{eA}$ \\
\hline AP Z & $32,22 \mathrm{dA}$ & $23,73 \mathrm{~dB}$ & $19,61 \mathrm{eB}$ & $35,51 \mathrm{eA}$ & $0,00 \mathrm{~dB}$ & $0,00 \mathrm{~dB}$ & $0,00 \mathrm{eB}$ & $39,05 \mathrm{bA}$ \\
\hline AP 61 & 41,97bB & $36,88 \mathrm{cB}$ & $38,76 \mathrm{cB}$ & $52,36 \mathrm{dA}$ & 51,13bA & $45,29 \mathrm{bA}$ & $46,19 \mathrm{cA}$ & $41,88 \mathrm{bA}$ \\
\hline Cent.Ser. & 75,13aA & $40,12 \mathrm{cB}$ & $32,60 \mathrm{~dB}$ & $80,66 \mathrm{aA}$ & $0,00 \mathrm{dA}$ & $0,00 \mathrm{dA}$ & $0,00 \mathrm{eA}$ & $0,00 \mathrm{eA}$ \\
\hline T. Tarumã & $27,65 \mathrm{~dB}$ & $19,23 \mathrm{eC}$ & $31,26 \mathrm{~dB}$ & $56,47 \mathrm{cA}$ & $0,00 \mathrm{~dB}$ & $0,00 \mathrm{~dB}$ & $0,00 \mathrm{eB}$ & $45,69 \mathrm{bA}$ \\
\hline Trit. 399 & $22,58 \mathrm{dC}$ & $0,00 \mathrm{fD}$ & $57,02 \mathrm{aA}$ & $43,45 \mathrm{eB}$ & $0,00 \mathrm{dA}$ & $0,00 \mathrm{dA}$ & $0,00 \mathrm{eA}$ & $0,00 \mathrm{eA}$ \\
\hline Trit. 981 & $0,00 \mathrm{eC}$ & $0,00 \mathrm{fC}$ & 49,03bB & $71,19 \mathrm{bA}$ & $0,00 \mathrm{dA}$ & $0,00 \mathrm{dA}$ & $0,00 \mathrm{eA}$ & $0,00 \mathrm{eA}$ \\
\hline Média & 34,27 & CV(\%) & 14,12 & & Média & 18,44 & CV(\%) & 24,81 \\
\hline
\end{tabular}

*For.: forrageiras: Az Co: az. Comum; Az SG.: az. São Gabriel; AB 2: av. branca FAPA 2; AB 43: av. branca Fundacep FAPA 43; AB 126: av. branca IPR 126; AB Ig.: av. branca UTF Iguaçu; AP Co.: av. preta Comum; AP Mo.: av. preta UPF 21-Moreninha; AP Pla.: av. preta Planalto; AP Cox.: av. preta Coxilha; AP Z.: av. preta Agro Zebu; AP 61: av. preta IAPAR 61; Cent. Ser.: cent. Serrano; T. Tarumã: trigo BRS Tarumã; Trit. 399: trit. TCL 399 e Trit. 981: trit. Pólo 981. **Médias seguidas por letras distintas maiúsculas na horizontal e letras minúsculas na vertical constituem grupo estatisticamente heterogêneo $(\mathrm{P}<0,05)$.

(Tabela 2) foram obtidas quando as forrageiras foram semeadas em junho, exceto para o azevém Comum, que teve maiores rendimentos diários quando semeado em abril e maio. Sendo que, para o mês de agosto, o centeio Serrano, semeado em junho, foi a forrageira que apresentou a maior produção com $74,21 \mathrm{~kg} \mathrm{ha}^{-1} \mathrm{dia}^{-1} \mathrm{de}$ MS e a aveia preta Agro Planalto a menor, com 14,58kg ha $^{-1}$ dia $^{-1}$ de MS, quando semeada em abril. AGUINAGA et al. (2008) obtiveram, durante o período de 23 de agosto a 26 de setembro, taxa de acúmulo média de $65,68 \mathrm{~kg} \mathrm{ha}^{-1} \mathrm{dia}^{-1} \mathrm{de}$ MS e CARVALHO et al. (2010) obtiveram taxa de acúmulo diária de $63,85 \mathrm{~kg} \mathrm{ha}^{-1} \mathrm{dia}^{-}$ ${ }^{1}$ de MS (de 5/8 a 8/9), em quatro alturas de manejo de pastagem de aveia-azevém, em culturas solteiras. 
Para o mês de setembro, observouse que muitas forrageiras da primeira, segunda e terceira época de semeadura não estavam mais produzindo, pois já haviam encerrado seu estágio vegetativo (Tabela 2). A quarta época de semeadura foi a que proporcionou maiores TA diária para o mês de setembro para todas as forrageiras, exceto para o azevém São Gabriel e triticale TCL 399, que apresentaram maiores acúmulos diários, quando semeadas nos meses de março e maio, respectivamente. A maior TA foi obtida pelo centeio Serrano na quarta época com 80,66 $\mathrm{kg} \mathrm{ha}^{-1} \mathrm{dia}^{-1}$ de MS, $61,43 \mathrm{~kg} \mathrm{ha}^{-1} \mathrm{dia}^{-1}$ de MS a mais que o trigo, que obteve a menor produção quando semeado em abril, indicando que essa espécie, apesar de ser considerada de ciclo precoce (FLARESSO et al., 2001), quando semeada tardiamente, é uma ótima alternativa para o forrageamento de primavera. CARVALHO et al. (2010) obtiveram produções de $65,05 \mathrm{~kg} \mathrm{ha}^{-1} \mathrm{dia}^{-}$ ${ }^{1}$ de MS, em pastagem de aveia +azevém, valores bastante semelhantes aos obtidos neste trabalho pelo azevém sob regime de cortes. Para o mês de outubro, esse mesmo autor obteve $78,7 \mathrm{~kg} \mathrm{ha}^{-1} \mathrm{dia}^{-1}$ de MS em pastagem de aveia+azevém maneja a $20 \mathrm{~cm}$ de altura.

No mês de outubro, foram poucas as forrageiras que apresentaram acúmulo de forragem (Tabela 2). Observou-se que, independente da época de semeadura, os azevéns, as aveias brancas IPR 126 e UTF Iguaçú, e a aveia preta Iapar 61 apresentaram valores de TA diária de forragem bastante satisfatórios durante esse mês, devido a sua longevidade de período vegetativo, demonstrando serem ótimas alternativas para o forrageamento de primavera.

Essas variações sobre acúmulo de forragem mostram a importância da definição das melhores datas de semeadura e forrageiras, além das possíveis misturas de forrageiras em concordância com a dinâmica da forrageira no decorrer do tempo. A dinâmica de produção torna possível dimensionar áreas para cada cultivar, bem como, fazer suposições sobre misturas destas com outras forrageiras para melhor uniformizar a produção de forragem no tempo.

\section{CONCLUSÃO}

Ocorrem diferenças nas distribuições da produção de forragem no tempo de acordo com a forrageira utilizada e a época de sua implantação. Semeaduras mais precoces tendem a disponibilizar maiores quantidades de forragem durante o outono e inverno, e semeaduras mais tardias durante o inverno e primavera. A melhor época de implantação para a maioria das forrageiras foi a de março, proporcionando maior produtividade e longevidade de produção. As aveias brancas IPR 126 e UTF Iguaçú, a aveia preta IAPAR 61, as cultivares de azevém e centeio avaliadas destacaram-se em relação às demais tanto em produtividade como em longevidade de produção de forragem, apresentando, em média, produção diária de forragem de 51,4kg ha-1 após a primeira utilização.

\section{REFERÊNCIAS}

AGUINAGA, A.A.Q. et al. Componentes morfológicos e produção de forragem de pastagem de aveia e azevém manejada em diferentes alturas. Revista Brasileira de Zootecnia, v.37, n.9, p.1523-1530, 2008. Disponível em: <http://www.scielo.br/ pdf/rbz/v37n9/a02v37n9.pdf>. Acesso em: 28 out. 2010. doi: 10.1590/S1516-35982008000900002.

BALBINOT JUNIOR, A.A. et al. Integração lavoura-pecuária: intensificação de uso de áreas agrícolas. Ciência Rural, v.39, n.6, p.1925-1933, 2009. Disponível em: <http://www.scielo.br/pdf/ cr/2009nahead/a229cr838.pdf $>$. Acesso em: 25 jan. 2011. doi: 10.1590/S0103-84782009005000107.

BHERING, S.B. et al. Mapa de solos do Estado do Paraná: legenda atualizada. Rio de Janeiro: EMBRAPA/IAPAR. 2008. 74p.

BORTOLINI, P.C. et al. Cereais de inverno submetidos ao corte no sistema duplo propósito. Revista Brasileira de Zootecnia, v.33, n.1, p.45-50, 2004. Disponível em: <http://www.scielo.br/pdf/rbz/ v33n1/a07v33n1.pdf $>$. Acesso em: 30 jan. 2011. doi: 10.1590/ S1516-3598200400010000.

CARVALHO, P.C.F. et al. Características produtiva e estrutural de pastos mistos de aveia e azevém manejados em quatro alturas sob lotação contínua. Revista Brasileira de Zootecnia, v.39, n.9, p.1857-1865, 2010. Disponível em: <http://www.scielo.br/ pdf/rbz/v39n9/a01v39n9.pdf>. Acesso em: 28 out. 2010. doi: 10.1590/S1516-35982010000900001.

COMISSÃO DE QUÍMICA E FERTILIDADE DO SOLO. Manual de adubação e calagem para os Estados do Rio Grande do Sul e Santa Catarina. 10.ed. Porto Alegre: SBCS, 2004. 400p.

CRUZ, C.D. Programa Genes versão Windows: aplicativo computacional em genética e estatística. Viçosa: UFV, 2001. 648p.

DA SILVA, S.C.; NASCIMENTO JÚNIOR, D. Avanços na pesquisa com plantas forrageiras tropicais em pastagens: características morfofisiológicas e manejo do pastejo. Revista Brasileira de Zootecnia, v.36, Supl esp, p.121-138, 2007.

FLARESSO, J.A. et al. Época e densidade de semeadura de aveia preta (Avena strigosa Schreb.) e azevém (Lolium multiflorum Lam.) no Alto Vale do Itajaí, Santa Catarina. Revista Brasileira de Zootecnia, v.30, n.6, p.1969-1974, 2001. Disponível em: <http://www.scielo.br/pdf/rbz/v30n6s0/7406.pdf>. Acesso em: 27 dez. 2010. doi: 10.1590/S1516-35982001000800002.

FLORES, R.A. et al. Produção de forragem de populações de azevém anual no estado do Rio Grande do Sul. Revista Brasileira de Zootecnia, v.37, n.7, p.1168-1176, 2008. Disponível em: $<$ http://www.scielo.br/pdf/rbz/v37n7/05.pdf >. Acesso em: 28 out. 2010. doi: 10.1590/S1516-35982008000700005. 
KIRCHNER, R. et al. Desempenho de forrageiras hibernais sob distintos níveis de luminosidade. Revista Brasileira de Zootecnia, v.38, n.11, p.2371-2378, 2010.

MAACK, R. Geografia física do Estado do Paraná. Curitiba: Max Roesner, 1968. 350p.

NELSON, L.R. et al. Plant breeding for improved production in annual ryegrass. In: ROUQUETTE, F.M.; NELSON, L.R. (Eds.) Ecology, production, and management of Lolium for forage in the USA. Madison: Crop Science Society of América, 1995. 125p.

PIN, E.A. et al. Forage production dynamics of winter annual grasses sown on different dates. Revista Brasileira de Zootecnia, v.40, n.3, p.509-517, 2011.
PRIMAVESI, A.C. et al. Adubação de aveia em dois sistemas de plantio. Pesquisa Agropecuária Brasileira, v.37, n.12, p.17731778, 2002

ROCHA, M.G. et al. Produção e qualidade de forragem da mistura de aveia e azevém sob dois métodos de estabelecimento. Revista Brasileira de Zootecnia, v.36, n.1, p.7-15, 2007. Disponível em: <http://www.scielo.br/pdf/rbz/v36n1/a02v36n1.pdf >. Acesso em: 28 out. 2010. doi: 10.1590/S1516-35982007000100002.

ROSO, C. et al. Aveia preta, triticale e centeio em mistura com azevém. 1. Dinâmica, produção e qualidade de forragem. Revista Brasileira de Zootecnia, v.29, n.1, p.75-84, 2000. Disponível em: <http://www.scielo.br/pdf/rbz/v29n1/5734. pdf $>$. Acesso em: 28 out. 2010. doi: 10.1590/S151635982000000100011. 